\title{
LA SOLEDAD Y EL SONIDO
}

\author{
Eric González Herrero
}

Con lentitud meridiana se acerca la aguja que marca el paso de los segundos a su posición más norte y el minutero, dispuesto a trasladarse al compás de su hermano pequeño, aguarda pacientemente su turno. Más tarde ese mismo reloj de pared será arrojado al exterior volando por los aires, observado por aquel que lo arroja y que no puede volar preso del tiempo y de sus dañinas agujas. De fuera se filtra la luz en el interior de la sala, atravesando las ventanas someras, medio tapadas por unas cortinas negras colgantes, sujetas estas mediante cables que atraviesan a lo ancho un doble balcón, alto del suelo al techo y que tiembla por el viento que recorre la calle, de principio a final, que atraviesa las carnes de las personas que caminan de un lado a otro, sin mirar a lo alto, sin pensar que dentro de un estrecho cuarto de esa misma calle una persona duerme o al menos lo intenta, demasiado preocupado de su suerte, avasallado por la idea de seguir perteneciendo a este mundo o en cambio descubrir otros nuevos, más esbeltos y justos, más pausados y bellos, imaginándose si existirá algún remoto lugar en este planeta donde las realidades se vean a cámara lenta, rodado en mudo y donde las personas miren a los ojos, como la actriz cuando mira de frente a una cámara que la graba, sabedor el operador que presencia algo único y majestuoso, y, moviendo el cinematógrafo en su dirección intenta penetrar en una nueva y mágica realidad.

El silencio que reina en esta habitación no es molesto. Al menos no para quien ahí reside y que parece fundirse en él como se funde la cera alrededor de una vela. Tampoco es un silencio místico aunque suponga este un momento genuino y trascendental en su vida y siente esta ausencia de ruido como algo hermoso. Se esfuerza para no trastocarlo, lucha con todo su cuerpo para que nada interrumpa la escena, para que el silencio perdure y perdure, como creyendo que si se decidiera a levantarse daría un movimiento en falso todo se perdería, la esencia del momento desaparecería y no le quedaría más remedio que volver a acostarse y esperar a que el silencio vuelva. Mas es consciente de que para poder vivir debe moverse debe crear ruido y aprender a vivir con ese ruido, debe alzarse, coger esa valija marrón que le observa en el rincón de la sala, colocarla a su espalda, abrir

Segundo Premio del

I Concurso de Relatos Breves AEN. 
la puerta y marcharse. Comenzar un nuevo capítulo. Pero una vez estas acciones cometidas, el siguiente paso sería caminar por la calle y formar parte del resto de personas que solas o acompañadas transitan por la calzada y charlan de todo y de nada, creando ruidos necesarios y otros prescindibles, asesinando el tan preciado silencio que tanto tiempo llevó a los hombres a amar. Y esto es algo que no puede permitir, algo que ya no sabe cómo lograr. Se niega a formar parte de ese juego de sonidos vulgares y simples, le gustaría vivir eternamente en un lugar donde las personas no necesitarán de las palabras para expresar sus emociones, le gustaría vivir en un lugar donde la poesía fuera capaz de explicar los sentimientos sin tener que alzar la voz, simplemente intuyéndola y abrazándola, arrimándose a ella delicadamente.

En un grandioso esfuerzo el joven hombre se levanta. Resiste el ruido de sus pies rozando el suelo, de sus pasos: uno, dos, tres, cuatro, cinco pasos que invaden la sala de sonidos atronadores, como rayos enviados por Zeus, hijo de Cronos, dios del Olimpo, para castigar a los hombres por sus maldades y sus constantes debilidades, cinco pasos que le llevan a los pies del balcón y agradece que el sutil deslizar de las cortinas que lo cubren no hagan más ruido que unas hormigas que trabajan para poder mover un pequeño hueso de durazno unos centímetros más cerca de su hogar.

Una vez en pie y observando la vida, los movimientos de una ciudad que despierta, una terrible jaqueca desguaza su ser. «iOtra vez no!», piensa él, y esa simple reflexión hace que sus dolores no sólo se mantengan sino que se agudicen, como si un taladro enrabietado atravesara su sien y, entrando por su lóbulo occipital, roza la zona del cerebro que sirve de almacenamiento de la memoria. Se agarra la cabeza, la mueve de un lado para otro y abre la boca para chillar pero nada sale de su interior pues el simple hecho de gritar no haría más que acrecentar la locura del momento. De pronto tiene miedo de que ese taladro destruya sus recuerdos, que todas sus memorias se esfumen, que pierda la capacidad de actuar correctamente, pues si ese taladro masacra su memoria ya no sería capaz de distinguir entre lo bueno y lo malo, tanto sus aciertos como sus errores del pasado dejarían de existir para él y ya renunciaría a tener sentido común. Entonces intenta plasmar en su cine interno imágenes de su pasado. Se ve corriendo por la playa al amanecer después de una larga noche; en Lecce existe un olor a mar espumoso y a algas. En el comienzo del talón de la bota italiana y no se ve solo, una chica le acompaña y sus ojos son claros como dos anchos lagos del norte y sus labios frágiles y soñadores llaman a la caricia de no ser por el temor que uno siente de quebrarlos, a que sobre ellos surjan grietas, usados por el tiempo y causadas por sus frías e inertes manos. Y se quitan la ropa, y se introducen en el infinito y bullicioso Mar Mediterráneo. Se ve ahora en Serbia, en una pequeña ciudad al oeste de Belgrado, al borde de un diminuto barco que atraviesa el Danubio de lado a lado para arribar a un pequeño islote desierto donde se tirará a tomar el sol y ver 
MÁRGENES DE LA PSIQUIATRÍA Y HUMANIDADES

las estrellas aparecer pero no recuerda el nombre de la pequeña ciudad al oeste de Belgrado así que se golpea la cabeza, pensando que así la compleja máquina que es su cerebro carburará con más precisión y descubrirá entre recuerdos el nombre de dicha ciudad pero el esfuerzo es en vano. «Respira. Respira. Respira». La jaqueca desparece lentamente pero no lo hace su malestar cuando observa a los caminantes pasear por la calle, persiguiendo sus quehaceres, abrazando sus obligaciones como ciudadanos y olvidando su principal misión en esta vida: vivir. Esto le pone enfermo, aún no ha aprendido a tolerarlo, su tripa se retuerce, se la agarra y cierra los ojos. No quiere tener que mirar a esas gentes, se niega a formar parte de esas masas olvidadas. Malditos sean los olvidadizos que de tanto olvidar olvidaron que estaban olvidando. Olvidaron incluso que sentir es bueno, aunque sea sentir un taladro en un cerebro o la lenta descomposición de un hígado. Es este el órgano que él cree padecer en este instante, algo así como si un duende vertiera en su interior ácido sulfúrico y este se deslizara por la pared intestinal hasta llegar al hígado, y se imagina al duende sonriendo. Cierra las cortinas y ya no hay luz en el cuarto. No la necesita, no la quiere, es una luz de mentira, es un sol que no ilumina fielmente o que lo hace pero con desgana, como si el ser humano fuera ya indigno de ese sol.

No siempre se sintió así. O al menos no siempre sintió ese fuego recorrer todo su cuerpo, toda esa pólvora circulando por sus venas arrastrando los restos humillados de sus vasos sanguíneos. Hubo un tiempo en el que incluso participaba de ese mundo y donde el mayor de sus dolores oscilaba entre una esguince causada durante algún fallido baile o una leve y trivial jaqueca consecuencia por darse demasiado a las copas. Desde luego nada similar a lo que este pobre cuerpo sucumbe en estos instantes. Solía pasear largo y tendido por las estrechas calles del centro de la ciudad, bajo cielos azul sur o gris metal, dependiendo de la estación anual en que se encontrase, deteniéndose en su cafetería predilecta, aquella que se encontraba en la calle B, esquina con calle C. Le gustaba ese sitio. Era uno de los pocos lugares en la ciudad donde uno descubría la perfecta y rara combinación entre lo popular y lo tradicional, perfecto rincón para apreciar tanto la miseria como el encanto. Y a menos que sus dueños hubieran conocido la misma malograda suerte que él, aún seguirán sirviendo cafés a paseantes, turistas y vecinos, todos ellos ajenos a cualquier tipo de contorsión intestinal aguda, alejados de patologías tan puramente humanas salvo, huelga decirlo, la indiferencia. Pero ya entonces sentía esa duda en su fuero interno: «¿Tendré de verdad alma? ¿Guardaré en mi interior algo que me haga esencialmente único? ¿Existirá en mí espacio suficiente, algún recoveco escondido, para que en el quepa un alma?».Y entonces se detenía en todo aquello que lo rodeaba, miraba a su alrededor bajo el mundanal ruido en busca de algún gesto, movimiento o mirada que instaurara luz en su mente para encontrar una certeza inefable: la conclusión de que el ser humano posee alma. Pero sólo veía los mismos gestos, movimientos y miradas 
en todos y cada uno de cuantos pasaban por delante de su menuda mesa. Y él, que detrás de su mostrador se sentaba a esperar soluciones, sólo coleccionaba fracasos. Entonces, apurado, dejaba de mirar, cerraba los ojos e intentaba hacerse a la idea de alma como algo fantástico, casi de ciencia ficción, digno de alguna película que tendría como título En busca del alma perdida. Sólo veía disfraces distintos de un mismo concepto. A sus ojos nada parecía hacer a nadie único o siquiera particular e incluso, si prestaba especial atención a sus andares, descubría que no sólo todos compartían mismos gustos en cuanto a zapatos se refiere, si no que, y esto es algo que le chocó con colérica fuerza, todos caminaban a la misma velocidad, con los mismos intervalos de tiempo entre paso y paso y con la misma dedicación. «¿Dedicación o parsimonia?», se preguntaba él sin esperar réplica alguna. Pero al percatarse de que al menos no todos caminaban en la misma dirección, al ver que algunos subían la calle B mientras otros seguían camino recto por $\mathrm{C}$, una sonrisa de esperanza se dibujó entre sus mejillas. Pero aún sobrevolaba sobre su cabeza la cuestión del alma, pues aunque no todos siguieran una misma dirección, aun así seguían los largos caminos de las avenidas, pisaban las mismas piedras de las anchas plazas. Nadie se saltaba esos senderos construidos hacía más de dos siglos, ideados por los ancestros pero ya existentes desde mucho antes de la aparición de las ciudades. Nadie los sorteaba, nadie parecía ir más allá, nadie se planteaba crear nuevos caminos, vírgenes y brillantes. Esos eran los que eran y no había más.

Comenzó después su etapa de introspección de la realidad. Esa que se llama realidad no porque las otras sean imposibles o improbables sino porque es la obligada, la comandada por los sabios y la acatada por los pueblos. Por eso viene precedida del artículo la que la hace intocable, ineludible. Descubrió que si mantenía los ojos abiertos no vería más que la más absoluta representación de lo real, de lo cotidiano, continuos ejemplos de la vida sobre la tierra transformados en cuerpos vacuos sobre esa tierra. Observaba y tomaba notas sobre un áspero papel de lo que a su alrededor sucedía. Entre ellos podemos leer hoy lo siguiente: ... Hay mujeres con máscaras en la cara y con bolsas de plástico en los pies porque dicen no querer formar parte de esta tierra y piensan con sinceridad que ese plástico les aísla y que así no se pueden contaminar y hay hombres con trajes de ejecutivo que se pasean y que se creen víctimas de la envidia de los humanos y que creen dominar un mundo que ya no es ni mundo ni humano ni tierra y hay quien entierra bajo la tierra una piedra que simboliza un pasado que no es peor que este presente pero es pasado y que seguro es peor que el futuro y hay quien piensa que no hay futuro ni hay tiempo suficiente para pararse a pensar en el parado de turno que emplea su tiempo en buscar empleo y que no tendrá futuro ni tiene presente y sólo vive del pasado, y hay quien agradece ese pasado porque por el aprendió que el presente ya no es suficiente y hay quien piensa que el futuro aun no está escrito. Hay mendigos y artistas que sólo representan la élite de 
MÁRGENES DE LA PSIQUIATRÍA Y HUMANIDADES

los caídos, hay una aristocracia de los pobres y hay muchos otros, muchos más, callados y acallados que no se ven y que no tienen nada porque no hay nada más para ellos, y hay quien no cree en la caridad y hay quien ve con claridad como una persona se aporrea la cara de rodillas en el suelo y clama al viento con angustia que no hay esperanza. Los hay también que caminan solos por la avenida y consigo mismo hablan, hay quien piensa que si no lo hicieran la luna se caería y el mundo se saldría de su órbita y hay quien cree que simplemente están locos y furiosos porque por no haber no hay ni quien les escuche ni les entienda. Hay quien gime y se pinta la cara de negro, quien piensa que su ciudad es una enorme cueva sin escritos ni dibujos, donde no hay luz que entra y donde la oscuridad se mide por la cantidad de luciérnagas que uno atisba o por el tiempo que tardan en prender los ropajes de aquel que, mechero en mano, lo rasga y su cuerpo, antes hermoso, ahora toma forma de cenizas, y hay quien espera que de ahi se renazca y hay quien grita y dice ser Jesucristo reencarnado, venido de los cielos para dar una tercera oportunidad a los hombres. Y hay quien dice que tres son ya muchas y hay quien piensa que nunca serán suficientes...

Todas estas escenas eran algo que desde que él tenía razón de ser siempre habían existido, que formaban parte de su vida y de su mundo, que eran sombras incambiables y que no tenía él a su alcance las herramientas necesarias para poder transformarlas. Más dolor sentía al escuchar los sonidos que estas trágicas personas exhibían, más todavía que las imágenes en sí de su desesperación. Su visión estaba ya demasiado acostumbrada, sus ojos toleraban ya cualquier tipo de vejación, al fin y al cabo así es como los hombres habían educado a sus hijos. Sus oídos, en cambio, no estaban aún tan finamente educados. Se dio cuenta también de que si cerraba los ojos ya no veía nada, ninguna imagen se dibujaba en tiempo real en su cerebro y sólo poseía como pistas de lo que a su alrededor sucedía, la aleatoria e inconsciente sucesión de sonidos esculpidos por la ciudad. Esto le alegraba. Las imágenes, las visiones de un hombre no son convertibles, uno no puede mirar a una persona y que su cerebro dibuje los rasgos de otra, puede intentarlo pero no obtendrá más que un amasijo de ideas y recuerdos que batallan para formar la imagen de algo existente pero no visible. En cambio sí puede cerrar los ojos y escuchar el ruido de un coche, crearse una imagen-movimiento de ese sonido e inventar un coche de la nada, cualquier tipo de coche, azul o rojo, puede incluso ir más allá e imaginar quién conduce el coche, si es mujer u hombre, si conduce con la ventanilla bajada, si fuma o si va acompañada de su recién nacido. Con los ojos cerrados uno puede confundir sonidos, necesita de la vista para aplicar el sonido a algo, para dar a ese ruido una causa. Pero uno también puede mantenerlos cerrados e imaginar de dónde provienen, crear su realidad personal, esta sí más inamovible si cabe que la realidad obligada. Crear una nueva, genuina y propia, todo lo duradera que uno quiera y todo lo real que uno quiera. Las personas cambian, los ruidos tam- 
bién. Pero uno no puede cambiar a una persona, a los ruidos sí. Puede aplicar cualquier significado a cualquier ruido, puede intercambiarlos, jugar con ellos, crear nuevas ideas de ruidos y hacerlo con los ojos cerrados. «Tan sencillo como eso», pensaba él. De esta manera podría convertir al hombre, hacer de él un mito o una rata, darle un alma incluso podría. No más espacio para tragedias reales, no más lamentarse por la injusticia reinante. Es su vida, es su idea, son sus sonidos y gracias a ellos sobreviviremos.

Alquiló un pequeño cuarto de blancas paredes. Era de su intención el que no hubiere en su interior ningún tipo de muebles más que una cama. ¿Si iba a vivir con los ojos cerrados para qué necesitaba un decorado? La única regla manifiesta que tenía era que diera a la calle, que desde dentro se escucharan tanto los pasos del gentío como sus conversaciones más ininteresantes.

Encontró en un primer piso un cuarto que se ajustaba a su gusto. Como no sabía cuánto tiempo iba a permanecer en él trajo consigo una maleta marrón clara como granos de playa cargada de prendas de lo más básico y varias bolsas de plástico que después se encargaría de vaciar. Dentro de ellas varias latas de comida se apilaban en el suelo formando lo que podría haber sido la silueta de una obra del museo Pompidou en París. Pasaron los primeros días, aún seguía en el proceso de acostumbrarse a vivir la mayor parte del día con los ojos cerrados. Había roto una camiseta negra a lo largo formando una tela de cinco centímetros de ancho que se ató a su cabeza, tapando sus ojos y viviendo entonces en la más absoluta penumbra. Vivía sin hora y tomaba notas mentales de los sonidos exteriores hasta el punto en el que era capaz de saber cuándo comenzaba a caer la noche basándose en la afluencia de sonidos que indicaba mayor o menor tránsito. De esta manera sabía cuándo, ya pasadas las seis de la tarde, el cielo comenzaba a cubrirse de una paulatina oscuridad gracias al tráfico de horas puntas, a la superior velocidad de movimientos de los caminantes, ansiosos por llegar al hogar después de su jornada de trabajo. Podía incluso saber si era fin de semana, lo que significaba una mayor cantidad de personas en las aceras, ávidas de rellenar su corazón comprando materia. Aunque este no era el objetivo de su misión. Él debía aislarse de todo cuanto fuera propenso a crearle remordimientos, aceptar la marginación voluntaria para poder sobrevivir a una sociedad que él juzgaba enferma. Y para ello había tomado la decisión más complicada de su vida pero a la vez la más acertada a sus ojos: encerrarse y no salir hasta haber cambiado el sentido de los sonidos. Así, al escuchar el inconfundible retumbo del camión de la basura pasar ya no lo asociaba con basura ni con un camión sino con el momento que marcaba el final de su día, el momento de abrazar la cama y bajo las sábanas respirar. Pero a medida que los días pasaban, lo que antes para él era uno de los más placenteros momentos de la vida, emprender el infinito camino del sueño, se había convertido en un momento completamente absurdo y anodino. El estar horas y horas despierto con los ojos tapados le impedía disfrutar del sueño 
MÁRGENES DE LA PSIQUIATRÍA Y HUMANIDADES

e incluso llegar a conciliarlo le suponía una tarea inequívocamente obtusa. Debía entonces abrir los ojos, entumecidos y legañosos, observar el roído techo y escuchar el silencio en la noche.

Existen varios tipos de silencios: están los silencios incómodos, los más temidos por el hombre pues la ausencia de algo no suele indicar más que la soledad de ese algo, en este caso es la soledad de los hombres, tan preocupados por esta enfermedad que acrecienta su temor con respecto a este tipo de silencios. Existen también los silencios divinos, estos son hermosos y suelen ocurrir, por ejemplo, cuando existe un cierto misticismo entre personas que se miran a los ojos y no hablan porque las palabras no harían más que inundar de hipocresía un momento tan único como memorable. ¿Cómo es posible entonces escuchar en el silencio el interior lloroso de este joven?

Pasaron más días, incluso semanas, pero al no llevar la cuenta ya no sabía en qué estación se encontraba su ciudad. En ocasiones se quitaba su venda negra para intentar completar mediante imágenes lo que los sonidos no revelaban. El gris humeante del cielo se reflejaba sobre las vitrinas de los escaparates y la gente portaba abrigos gruesos, incluso alguno se paseaba con paraguas. Esto le llevó a la conclusión que el otoño estaba cerca. Pensó en todo aquello que le recordaba al otoño. Pensó en la misma lluvia de cada año, en cómo el sutil cantar de los pájaros comenzaba a apagarse, se acordó de los árboles y de sus hojas caer. En su cabeza sonaba la melodía de Les feuilles d'automne, una canción francesa que su madre le cantaba cuando él era aún niño y era feliz, cuando no tenía mayor preocupación que la de sonreír incansablemente, y recordó el sonido de los árboles y de las hojas caer. «Al menos hay ciertos sonidos que nunca cambiarán».

La comida empezaba a agotarse. Comenzaba a crearse en la sala un olor a crudo y el orinal -que durante tantos días y semanas le había servido como baño improvisado y que vaciaba cada noche por el mirador, antes de la llegada del camión de la basura- comenzaba a albergar restos y costras. Era el olor de los excrementos, pero al menos eran suyos y de nadie más, por lo que era fácil habituarse a ellos.

Poco a poco iba sintiendo y de manera más firme un dolor agudo en la parte izquierda de su cabeza. No había traído ningún tipo de remedios consigo, no pensaba que los fuera a utilizar y en parte también quería sentir el sufrimiento como algo suyo. Si su misión era entender y escuchar la angustia de la gente para poder cambiarla, primero debía comenzar con la suya propia. Así que no le quedó más remedio que habituarse a sus olores y a sus dolores.

Y es aquí cuando volvemos al principio de la historia: él tumbado en la cama, su maleta marrón arenosa apoyada en el rincón y apenas tres latas de conserva en la base de lo que antes había sido su obra de arte. Su tiempo se agotaba, iba a llegar el momento en el que tendría que descender a la calle, formar parte 
del todo e ir en busca de provisiones. En un arrebato de ira y desesperación lanzó por el marco del ventanal el reloj que durante semanas le había acompañado pero del que no quería sentirse preso. Al hacer esto esperó que no cayera sobre ningún viandante así que se asomó por el balcón y lo vio destrozado contra el suelo. Las agujas sueltas y sus tripas abiertas dejaban ver el complejo funcionamiento de un antiguo reloj de pared suizo. Pero su oído, más agudizado que nunca, no era capaz de soportar el ladrido incesante de los coches. Las bolsas de las compras rozando unas con otras le hacía pensar en bolsas repletas de órganos humanos que aún seguían sufriendo en el interior de algún cuerpo, antaño anfitrión de los mismos. Había sido capaz de mantener la distancia y de asemejar sonidos a lo que él quisiera. Esos coches no tendrían por qué ser ruidos de coches, de igual modo con las bolsas. Había practicado demasiadas semanas como para que eso no resultara un problema. Pero no era tarea sencilla y el aire de la calle era más viciado todavía que el de la sala, y esto le invadía de miedo. No sabía si sería capaz de sobrevivir a esa jungla de asfalto, aunque fuera por diez minutos. Sentía que su cabeza no funcionaba como lo había hecho meses atrás, sentía que todo le hastiaba, que el haber vivido en soledad durante tanto tiempo le causaría un aneurisma en el momento de salir a la ciudad. Tenía la sensación de que el fin del mundo estaba cerca y se negaba a morir de la misma manera que todo el resto de personas que veía día a día en su calle, no quería ser un número más en la libreta de la morgue. Si iba a morir, quería hacerlo de la manera más personal posible.

Durante un tiempo la idea del suicidio sobrevoló en su mente pero siempre encontraba nuevas razones y nuevos sonidos para no dar por finiquitado su trabajo, para seguir viviendo unos días más. Se acordaba de las hojas caer y de su peculiar sonido, ese que nunca ha cambiado y esperaba que nunca cambiara. «El campo - pensaba - puede ser una solución válida, vivir en medio de la naturaleza, rodeado de pureza y de aires frescos, sin sonidos exteriores, sin falsedades usuales, junto a la flora y fauna de un bosque». Convertirse en un ermitaño moderno le llamaba la atención. No tendría que rendir cuentas a nadie pues sus padres murieron cuando él era muy joven y se las había apañado para cerrar cualquier tipo de relación de amistad antes de emprender esta aventura. Decía que si la verdadera amistad era el espejo de uno mismo, quería dejar de encontrarse en los ojos de otros y para eso debía de cortar relaciones de la manera más dura y brusca posible. Así le dijo a su novia de entonces que ya no la quería, que nunca la había querido y que si estaba con ella era porque debía estar con alguien, o al menos eso era lo que había leído en los libros y visto en las películas, que el amor es necesario porque es a lo que nos han acostumbrado desde pequeños, pero que si por él fuera viviría en un mundo sin amor o al menos con amor para todo el mundo, un amor equilibrado y repartido entre todas las personas de la tierra, un amor fraternal y universal, desde luego no un amor dirigido con exclusividad a una única persona. A su mejor amigo le 
MÁRGENES DE LA PSIQUIATRÍA Y HUMANIDADES

dijo todavía mayores barbaries, imposibles de reproducir con palabras, bastaba sólo con observar detenidamente la mirada de hielo con la cual le expresó su hartazgo con respecto a las relaciones de amistad y escuchar entre silencios la incomprensión de su eterno amigo de infancia. En estos momentos se acuerda de ellos, imagina qué es lo que estarán haciendo ahí fuera, imagina si seguirán hablando de él y si lo harán con maldad y rencor o lo harán con una cierta gracia, recuerdos de tiempos pretéritos. Se pregunta si su persona habrá sido lapidada por aquellos que él creía querer y que sabía a él le querían. ¿Cómo llegar hasta el bosque? ¿Cómo hacer para poder comenzar una vida nueva sin tener que utilizar los mecanismos de una vida que él quería pasada? Se acuerda también de un hombre que una vez le explicó lo que era realmente el asfalto: un material viscoso, pegajoso y oscuro usado como aglomerante para la creación de autovías, presente en el petróleo crudo y compuesto mayoritariamente de bitumen. Decía que la palabra asfalto le recordaba al lago Asfaltites, en el Mar Muerto, y que quizás por eso lo llamaron asfalto, pues no servía para otra cosa que acabar con las vidas humanas, para asesinar la libertad de un hombre haciéndole creer que es en verdad libre y dichoso y que el asfalto es la única materia para construir caminos de libertad y de unión, masas estrechas y curvadas de asfalto sobre un mar muerto.

Se le cae el cuchillo que le servía de abrelatas al suelo, ya no le quedan uñas, se las ha roído todas, y ese choque bestial del metal contra el parqué le sienta como un escopetazo en sus rótulas. Esta vez sí chilla de dolor y de amargura. Comienza a temblar, sus manos y dedos no se mueven acordes a su voluntad. Al borde del desmayo se acerca arrastrándose a la cama y ahí se queda. Las lágrimas desfilan sobre su perfil. Ha llegado demasiado lejos en cuanto al estudio de los sonidos si un simple incidente como el que acaba de ocurrir le causa tamaña sensación de angustia. Es temprano por la mañana, el único eco del viento, libre e inocente como siempre así se lo indica. Se pone en pie y abre el balcón, como queriendo ser hipnotizado por la creación del dios Helios. Agarra con su mano derecha el cuchillo que aun reposaba sobre el suelo, lo alza hasta permanecer en paralelo con sus ojos, frente al balcón de la calle, en su perfil derecho y, empuñándolo como quien empuña la bayoneta antes de abandonar la trinchera para correr en dirección en campo enemigo, hace que la fina hoja de su arma se introduzca en el interior de su oreja derecha, dejándolo caer acto seguido sobre el mismo parqué aunque el ruido de esas dos fuerzas chocando le suena ahora más hueco que hace unos pocos minutos. De su interior cae un chorro de sangre oscura, casi marrón pino, pierde el equilibrio y cae al suelo, a pocos centímetros del arma suicida. De un glorioso esfuerzo lo agarra y hace lo mismo sobre su oreja izquierda. La misma cantidad de sangre brota pero al menos esas interminables jaquecas parecen ahogarse en el río de plasma. Ya no siente nada. Ya no escucha nada. Ni siquiera el viento enfurecido 
MÁRGENES DE LA PSIQUIATRÍA Y HUMANIDADES

de esa mañana otoñal, apenas siente ya dolor pero está seguro, aunque no pueda verse, que una sonrisa inconsciente surge de entre sus temblorosos labios. Y piensa moribundo: «El silencio, el silencio... he aquí un sonido que muy a pesar de los hombres nunca cambiará». 